\title{
A novel way to avoid reoperation for biliary strictures after liver transplantation: cholangioscopy-assisted guidewire placement
}

Biliary tract complications after liver transplantation remain a major therapeutic issue significantly affecting graft and patient survival [1]. Strictures of the bile duct account for about $40 \%$ of biliary complications after liver transplantation [2]. Today, endoscopic retrograde cholangiography (ERC) has widely replaced surgery and percutaneous techniques as the treatment of choice for such patients [3]. However, highly fibrotic strictures of the anastomotic region frequently preclude passage of the guidewire. In these cases, percutaneous transhepatic cholangiography (PTC), endoscopic ultrasound-guided biliary drainage, or indication for resection of the stenosis-bearing extrahepatic biliary segment with subsequent biliodigestive anastomosis are applied, all of which are associated with increased morbidity.

We present here three patients with late fibrotic strictures of the anastomotic region after deceased donor liver transplantation ( $\triangleright$ Table 1 ). ERC revealed high grade stenosis that was impossible to pass despite various ERC maneuvers, including use of hydrophilic guidewires, occlusion balloons, and rotatable sphincterotome (> Fig. 1). Using singleoperator cholangioscopy (SpyGlass DS direct visualization system; Boston Scientific), the pin-sized orifice could be identified in all cases ( $\triangleright$ Fig. 2 ). Only direct visual guidance allowed placement of a 0.025 -inch hydrophilic guidewire through the stricture in two patients ( Fig.3). In one patient, pre-dilation of the stricture by means of biopsy forceps allowed subsequent guidewire placement ( $\triangleright$ Fig.2b). Gradual mechanical dilation and stent placement were achieved in all three cases, avoiding alternative more invasive and riskier procedures. Consequently, direct cholangioscopy resulted in a therapeutic success in all three cases after failure of standard ERC.
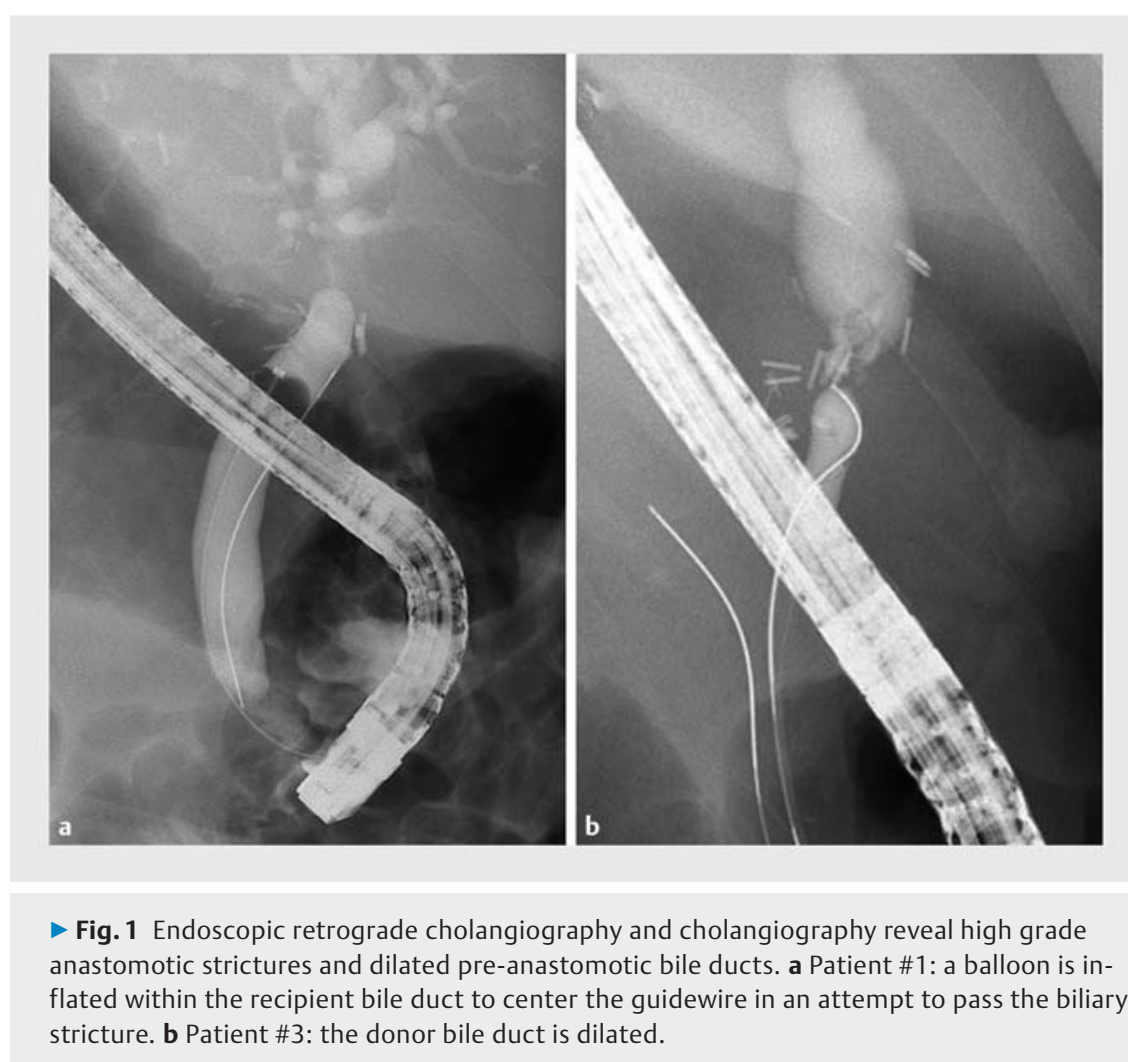

- Fig. 1 Endoscopic retrograde cholangiography and cholangiography reveal high grade anastomotic strictures and dilated pre-anastomotic bile ducts. a Patient \#1: a balloon is inflated within the recipient bile duct to center the guidewire in an attempt to pass the biliary stricture. b Patient \#3: the donor bile duct is dilated.

From our experience we conclude that single-operator cholangioscopy (SpyGlass) seems to be a useful therapeutic option in patients with highly fibrotic strictures post-liver transplantation. No procedure-related complication occurred. No further interventions, in particular PTC or surgery, with associated morbidity were needed.

Endoscopy_UCTN_Code_TTT_1AR_2AG

- Table 1 Cholangioscopy-assisted guidewire placement in three patients with biliary stricture after liver transplantation: patient characteristics.

\begin{tabular}{|l|l|l|l|l|l|}
\hline Patient no. & Age, sex & $\begin{array}{l}\text { Reason for liver trans- } \\
\text { plantation }\end{array}$ & $\begin{array}{l}\text { Liver transplantation to } \\
\text { biliary stricture interval, } \\
\text { months }\end{array}$ & $\begin{array}{l}\text { Internal stenting per- } \\
\text { formed at liver trans- } \\
\text { plantation? }\end{array}$ \\
\hline $\mathbf{1}$ & operator cholangios- \\
copy?
\end{tabular}



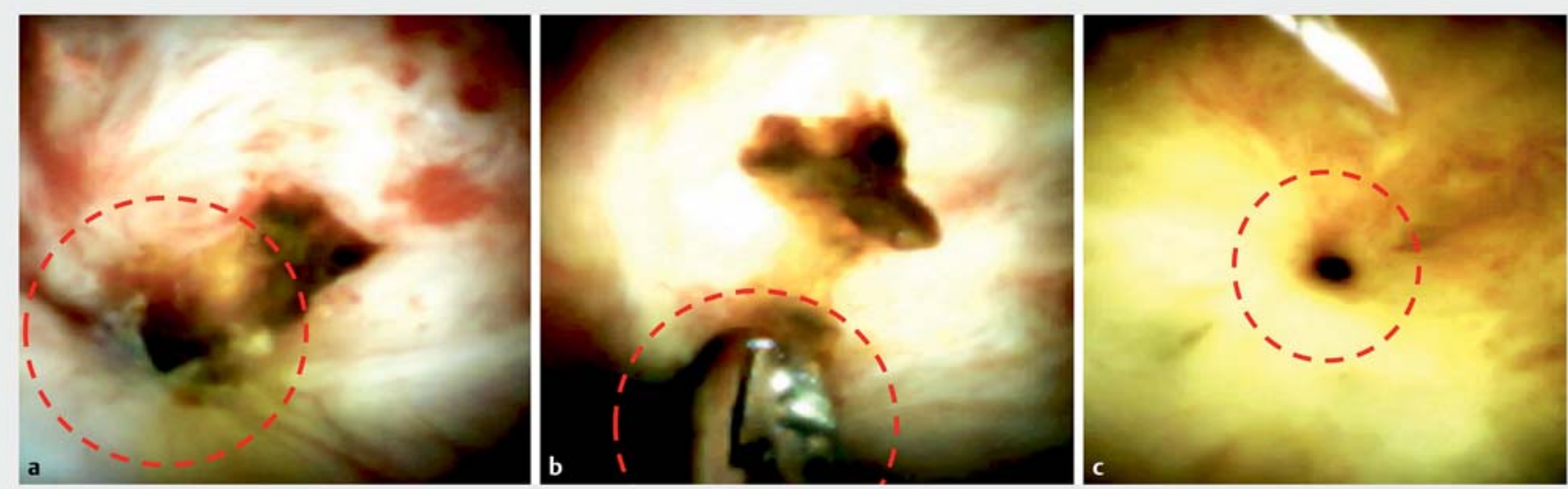

- Fig. 2 Direct cholangioscopy reveals pin-sized stricture orifices (red circles). a Patient \#2: the orifice is sealed with sludge and detritus; it is located in the left lower part of the image. b Patient \#2: the biliary stricture is dilated with a biopsy forceps. c Patient \#3.
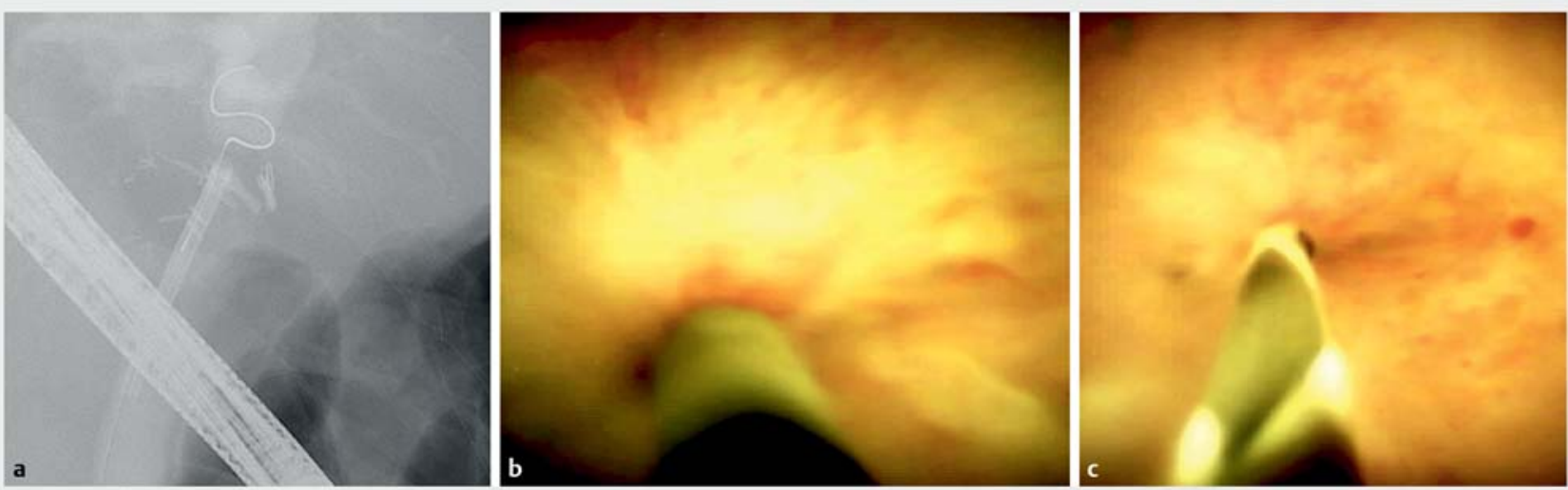

- Fig. 3 a Radiography: successful insertion of the guidewire in patient \#1. b, c Direct cholangioscopy: successful insertion of the guidewire in patient \#3.

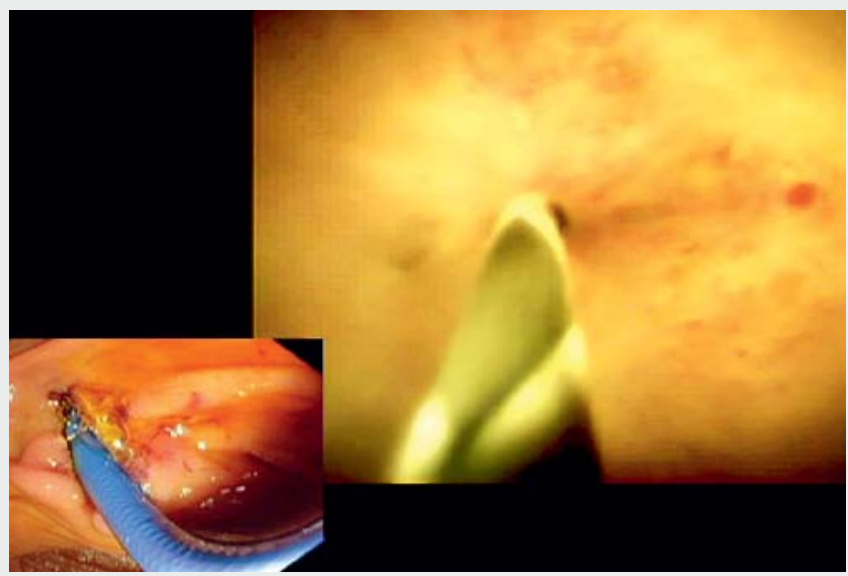

Competing interests

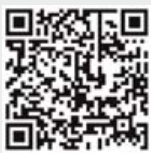

$\checkmark$ Video 1 Cholangioscopy-assisted guidewire placement in a patient with biliary stricture after liver transplantation.

\section{None}

The authors

Florian Rainer ${ }^{1,2}$, Andreas Bles| ${ }^{1,2}$, Walter Spindelboeck ${ }^{1,2}$, Peter Schemmer ${ }^{2,3}$, Peter Fickert $^{1,2}$, Florian Schreiber ${ }^{1,2}$

1 Division of Gastroenterology and Hepatology, Department of Internal Medicine, Medical University of Graz, Austria

2 Transplant Center Graz, Medical University of Graz, Austria

3 Division of Transplant Surgery, Department of Surgery, Medical University of Graz, Austria 


\section{Corresponding author}

\section{Florian Rainer, MD}

Division of Gastroenterology and

Hepatology, Department of Internal

Medicine, Medical University of Graz,

Austria, Auenbruggerplatz 15, $8036 \mathrm{Graz}$,

Austria

Fax: +43-316-38512648

florian.rainer@medunigraz.at

\section{References}

[1] Duffy JP, Kao K, Ko CY et al. Long-term patient outcome and quality of life after liver transplantation: Analysis of 20-year survivors. Ann Surg 2010; 252: 652 - 661
[2] Sauer P, Chahoud F, Gotthardt D et al. Temporary placement of fully covered self-expandable metal stents in biliary complications after liver transplantation. Endoscopy 2012; 44: 536- 538

[3] Houben P, Gotthardt DN, Radeleff B et al. Complication management after liver transplantation. Increasing patient safety by standardized approach and interdisciplinary cooperation. Chirurg 2015; 86: 139-145

\section{Bibliography}

DOI https://doi.org/10.1055/a-0896-2360

Published online: 4.6.2019

Endoscopy 2019; 51: E314-E316

(c) Georg Thieme Verlag KG

Stuttgart · New York

ISSN 0013-726X

\section{ENDOSCOPY E-VIDEOS}

https://eref.thieme.de/e-videos

回的 Endoscopy E-Videos is a free access online section, reporting 国: on interesting cases and new techniques in gastroenterological endoscopy. All papers include a high quality video and all contributions are freely accessible online.

This section has its own submission website at https://mc.manuscriptcentral.com/e-videos 